\title{
Corn leaf aphid, Rhopalosiphum maidis (Hemiptera: Aphididae), is a key to greenbug, Schizaphis graminum (Hemiptera: Aphididae), biological control in grain sorghum, Sorghum bicolor
}

\author{
Gerald J. MICHELS, JR. and JAMES H. MATIS
}

\author{
Texas Agricultural Experiment Station, P. O Drawer 10, 2301 Experiment Station Road, Bushland, TX 79012, USA; \\ e-mail: gmichels@tamu.edu \\ Department of Statistics, Texas A\&M University, College Station, TX 77843-3143, USA; e-mail: matis@stat.tamu.edu
}

Key words. Corn leaf aphid, greenbug, coccinellids, biological control, grain sorghum, pest management

\begin{abstract}
In the sorghum/aphid/ladybeetle ecosystem found in the Texas High Plains Region of the United States, we found that the corn leaf aphid, Rhopalosiphum maidis (Fitch), is a key aphid species that provides a critical early-season food source for native coccinellids. From 1988 to 2000 data on the seasonal abundance of sorghum-infesting aphids and ladybeetles were collected from a total of 21 irrigated and 12 rain-fed grain sorghum fields. The data indicated that successful biological control of the greenbug by coccinellids is normally dependent on early-season colonization of the sorghum field by corn leaf aphids. When corn leaf aphids exceeded 100/plant before sorghum boot stage greenbugs never exceeded 125 aphids/plant. In all cases where greenbugs were found in densities that would cause economic damage to sorghum (>250/plant), corn leaf aphids reached a density of 100 or more per plant after sorghum reached the boot stage. In irrigated fields, the first record of coccinellid eggs and peak coccinellid abundance were positively and significantly $(\mathrm{p}=0.05)$ correlated to the day of the year when corn leaf aphids reached or exceeded a minimum of 100/plant and corn leaf aphid peak abundance in both irrigated and rainfed fields. On the other hand, greenbug peak abundance was significantly correlated only to coccinellid peak abundance in irrigated fields. Regression analyses indicated that in paired analyses of irrigated and rain-fed sorghum fields, an increase of one aphid at time $t$, resulted in an increase in coccinellid peak abundance from 0.024 to 0.025 per $15 \mathrm{~m}$ of row at time $t+2$ depending on aphid species, if corn leaf aphids reached a level of 100 or more per plant by sorghum boot stage and irrigation parameters. We concluded that corn leaf aphids are an important early-season food source for predaceous coccinellids, drawing these predators into the fields where they feed on the aphids and deposit eggs, engendering a captive larval population that is present when greenbug first begin to enter the field later in the season.
\end{abstract}

\section{INTRODUCTION}

At times, pest management practices can concentrate too narrowly on a specific predator prey interaction without bringing into account other factors. The greenbug, Schizaphis graminum (Rondani), is a serious economic pest of grain sorghum, Sorghum bicolor (L.) Moench, in the United States Great Plains. Existing biocontrol agents, primarily coccinellids in the genus Hippodamia, can keep this pest at sub-economic levels if there is a proper understanding of the ecological interactions among the native predaceous coccinellids and their aphid prey.

In the early 1980s in the High Plains of Texas, aphids infesting grain sorghum, Sorghum bicolor (L.) Moench, regardless of species, were controlled by aerially-applied insecticides. Timing for the applications was based on seeing "slick leaves" caused by the deposition of corn leaf aphid, Rhopalosiphum maidis (Fitch), honeydew. This was an unsophisticated control strategy which typically required multiple insecticide applications for aphids and oftentimes resulted in late-season infestations by Banks grass mites, Oligonychus pratensis Banks, for which there were no effective control measures (Buschman \& DePew, 1990). Cronholm et al. (1998) note that corn leaf aphids rarely cause economic loss and can be considered helpful by attracting coccinellids. Cate et al. (1973) and Wilde \& Ohiagu (1976) both concluded that using insecticides to control corn leaf aphids did not increase sorghum yield nor did corn leaf aphid infestations caused significant damage to grain sorghum. In addition, applying insecticides for corn leaf aphids disrupts or eliminates predators and parasitoids which attack greenbugs in sorghum or migrate and aid in biological control of aphids in crops such as cotton (Cronholm et al., 1998).

Research by Kring et al. (1985), Kring \& Gilstrap (1986), and Rice \& Wilde (1988) clearly indicated a relationship between corn leaf aphids and predaceous coccinellids which was a key to greenbug, Schizaphis graminum (Rondani), biological control. This research prompted us to examine the interactions among the aphids and predators over an extended period of time and by irrigated and rain-fed agronomic practices, to determine if biological control of greenbugs in grain sorghum could be better understood and enhanced by conserving natural enemies. This paper presents the results of a multiple-year study of the seasonal abundance of sorghum-feeding aphids and the associated predacious coccinellids. 


\section{MATERIAL AND METHODS}

\section{Field data collection}

From 1988 to 2000, with the exception of 1992, 33 "fieldyears" of data on aphids, predators and parasitoids were collected in irrigated and rain-fed grain sorghum fields. A list of the aphid, predator and parasitoid species collected during the research is found in Table 1. A "field year" is defined as one field sampled throughout the growing season. In Bushland, Potter Co., TX, data were collected for 12 years in irrigated and four years in rain-fed grain sorghum fields. In Etter, Moore Co., TX, data were collected for seven years in irrigated and six years in rain-fed grain sorghum fields. Two additional fields were sampled in Oldham Co. (irrigated) and in Gray Co., TX, (rain-fed) in 1994 and two fields were sampled in Parmer Co., TX, (one irrigated and one rain-fed) in 1995. Standard agronomic practices for grain sorghum production were followed each year.

Fifty consecutive plants down a field row (approx. $15 \mathrm{~m}$ ) from a random starting point were examined by hand. Predator and parasitoid numbers/plant were recorded on standardized data sheets. After completing predator and parasitoid sampling, 12 plants were randomly selected from within the 50-plant sample, cut off at the base, and all corn leaf aphids and greenbugs were counted. The process was repeated 12 times at each sampling date, giving a total of 600 plants sampled for predators and parasitoids and 144 plants sampled for aphids.

Different numbers of plants were sampled for natural enemies and aphids for three reasons:
1. To obtain accurate aphid counts, especially corn leaf aphids which are often found deep in the whorl, destructive sampling was necessary,

2. Time and personnel considerations,

3. Removing 600 plants per week from a particular field for destructive sampling during the season could have adverse effects on the distribution of aphid and beneficial insects.

The same sampling routine was carried out each year. We began observing fields in early June and sampling started when corn leaf aphids first began to appear in the field and continued on a weekly basis until greenbug densities dropped to zero for two consecutive weeks. At times, heavy rains prevented sampling on a strict seven-day interval. However, samples were taken as closely as possible to the planned sampling date (Table 2).

Analyses of parasitoids in relation to initiating greenbug biological control were omitted from this paper. Although parasitoids are important to the overall seasonal abundance of greenbugs, and to a lesser extent, corn leaf aphids, in this region, parasitoids occur late in the season and perform more of a "clean-up" function rather than being critical to suppression of greenbugs when they can most damage gain sorghum.

\section{Data analyses}

Pearson's Correlation Coefficients comparing corn leaf aphid peak abundance, the date when corn leaf aphids averaged $100 /$ plant, and greenbug peak abundance to the occurrence of the first predacious coccinellid eggs and the peak coccinellid predator abundance were determined using SAS ver. 8.0 (1999) PROC CORR. Regression analyses were performed using SPSS

TABLE 1. Aphid, predator and parasitoid species collected in grain sorghum fields in the Texas High Plains from 1988-2000.

\begin{tabular}{|c|c|c|c|c|c|c|}
\hline \multirow{2}{*}{$\begin{array}{l}\text { Family } \\
\text { Genus and species }\end{array}$} & \multirow{2}{*}{ Total recorded } & \multirow{2}{*}{$\begin{array}{c}\text { Percentage } \\
\text { of all samples }\end{array}$} & \multicolumn{4}{|c|}{ Percentage of } \\
\hline & & & Coccinellidae & all predators & parasitoids & aphids \\
\hline \multicolumn{7}{|l|}{ Aphididae } \\
\hline Rhopalosiphum maidis (Fitch) & 297,363 & 43.21 & & & & 53.19 \\
\hline Schizaphis graminum (Rondani) & 261,721 & 57.15 & & & & 46.81 \\
\hline \multicolumn{7}{|l|}{ Coccinellidae (adults) } \\
\hline Hippodamia convergens Guérin-Ménéville & 18,652 & 56.96 & 61.46 & 57.05 & & \\
\hline Hippodamia sinuata Mulsant & 9,962 & 36.58 & 32.82 & 30.47 & & \\
\hline Other & 996 & 12.71 & 3.28 & 3.05 & & \\
\hline Scymnus (Pullus) loweii & 342 & 5.26 & 1.13 & 1.05 & & \\
\hline Coleomegilla maculata Timberlake & 302 & 4.05 & 1.00 & 0.92 & & \\
\hline Coccinella septempunctata $\mathrm{L}$. & 60 & 2.37 & 0.20 & 0.18 & & \\
\hline Hippodamia parenthesis (Say) & 24 & 1.75 & 0.08 & 0.07 & & \\
\hline Olla v-nigrum (Mulsant) & 12 & 0.26 & 0.04 & 0.04 & & \\
\hline Coccinellidae egg masses & 1,689 & & & & & \\
\hline Coccinellidae larvae & 14,842 & & & & & \\
\hline Coccinellidae pupae & 4,170 & & & & & \\
\hline \multicolumn{7}{|l|}{ Chrysopidae } \\
\hline Chrysoperla sp. larvae & 1,103 & 40.15 & & 3.37 & & \\
\hline Chrysoperla sp. eggs & 9,775 & & & & & \\
\hline \multicolumn{7}{|l|}{ Nabidae } \\
\hline Nabis americoferus Carayon & 1,205 & 8.57 & & 3.68 & & \\
\hline Syrphidae (larvae) & 39 & 4.94 & & 0.12 & & \\
\hline \multicolumn{7}{|l|}{ Aphelinidae } \\
\hline Aphelinus varipes (Foerster) mummies & 19,590 & 11.03 & & & 19.48 & \\
\hline \multicolumn{7}{|l|}{ Braconidae } \\
\hline Lysiphlebus testaceipes (Cresson) mummies & 80,972 & 19.34 & & & 80.52 & \\
\hline
\end{tabular}

${ }^{1}$ Percentage of all samples containing the specified insect, 4224 samples total. 
TABLE 2. Day of the year for first and last occurrence of aphids and predacious coccinellids in grain sorghum at five sites in Texas, 1988-2000.

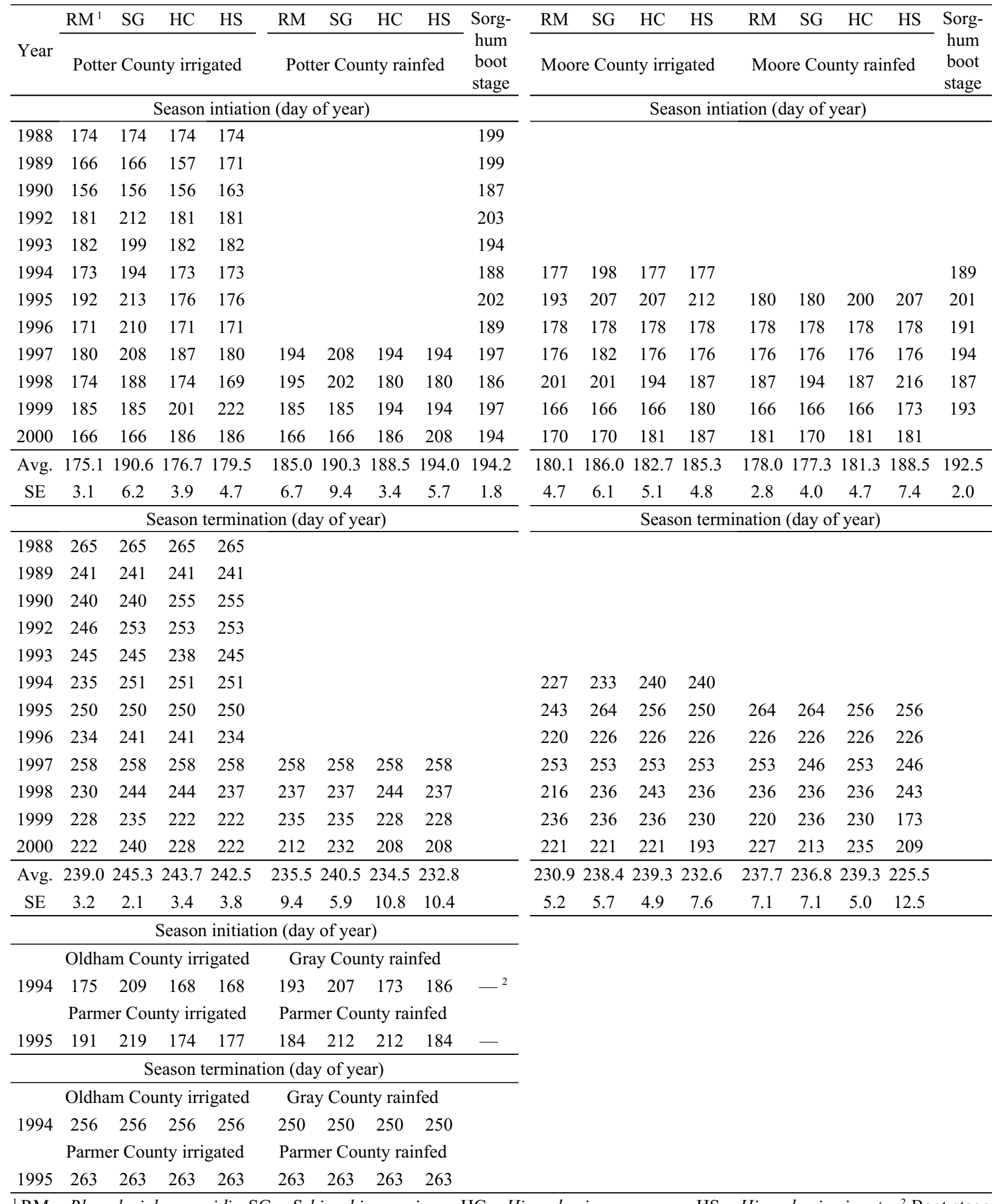

${ }^{1}$ RM - Rhopalosiphum maidis, SG - Schizaphis graminum, HC - Hippodamia convergens, HS - Hippodamia sinuata. ${ }^{2}$ Boot stage not recorded.

ver. 13.0 (2007). The procedure was to regress peak coccinellid abundance at sampling time $t$ on aphid abundance at sampling time $t-2$. This "look back" approach was employed using various steps back, with $t-2$ being found to be the most relevant. Prior to $t-2$, the predictions were too weak, and at $t-1$ and $t$ the predictions hold little practical value. This makes sense, in that predator abundance tends to follow prey abundance, and there should be some optimal "look back" time that provides the best fit of the data. 

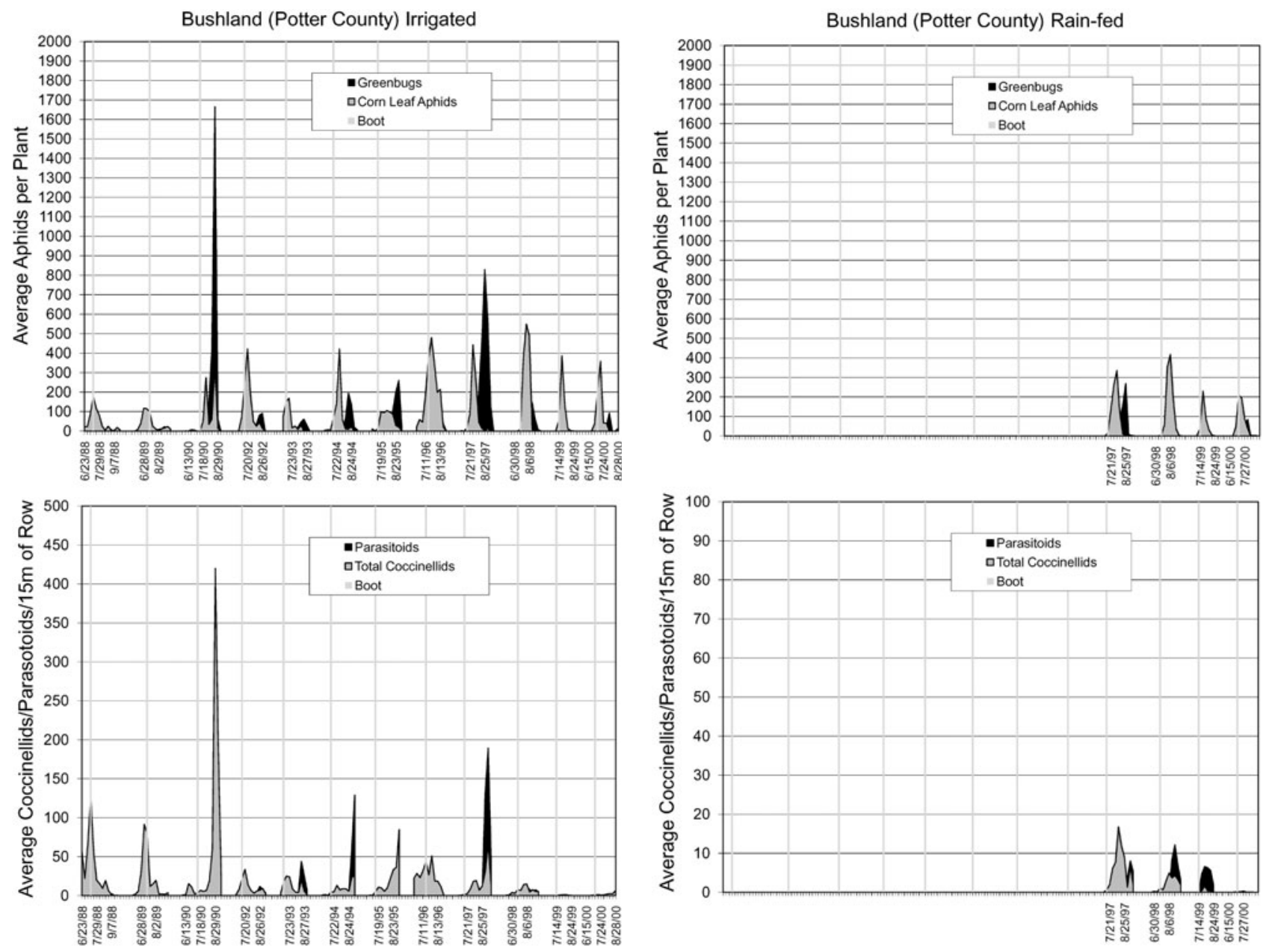

Fig. 1. Greenbug, corn leaf aphid, predacious coccinellid and parasitoid abundance in irrigated grain sorghum fields, Bushland, TX, 1988-2000. Sorghum boot stage represented by vertical lines.

\section{RESULTS AND DISCUSSION}

Figs 1-6 illustrate the seasonal occurrence and abundance of corn leaf aphids, greenbugs, predacious coccinellids and parasitoids in irrigated and rain-fed grain sorghum fields located in Bushland, Potter County, TX (Figs 1, 2); Etter, Moore County, TX (Figs 3, 4); and Gray, Oldham, and Parmer Counties, TX (Figs 5, 6).

In irrigated grain sorghum fields (Table 3), corn leaf aphid and greenbug peak abundance were significantly correlated to peak coccinellid abundance $(p=0.005$ and 0.008 , respectively). Corn leaf aphid peak abundance and the date when corn leaf aphid density averaged 100/plant were also significantly correlated to first coccinellid eggs in irrigated fields ( $p=0.007$ in both instances). Greenbug peak abundance was not significantly correlated to the appearance of the first coccinellid eggs.

In rain-fed sorghum fields, the same results were found with the exception that greenbug peak abundance was not significantly correlated to coccinellid peak abundance. The results from the correlation analyses coupled with the seasonal abundance of corn leaf aphids and greenbugs presented in Figs 1-6 may indicate a critical factor or

Fig. 2. Greenbug, corn leaf aphid, predacious coccinellid and parasitoid abundance in rain-fed grain sorghum fields, Bushland, TX, 1988-2000. Sorghum boot stage represented by vertical lines.

"trigger" in biological control of greenbugs in grain sorghum because the appearance of corn leaf aphids early in the season probably initiates coccinellid oviposition, thus ensuring a "captive" population of larvae that are present to feed on greenbugs as they colonize the field. Failure of corn leaf aphids to colonize a field, or approach an abundance of 100/plant by the boot stage of sorghum probably results in few coccinellids ovipositing, and greenbugs not being subjected to predation sufficient to keep their numbers below economically damaging levels.

For greenbug management in either irrigated or rain-fed grain sorghum, a seemingly handy "rule of thumb" is that greenbug biological control by coccinellids is successful and outbreaks do not occur when corn leaf aphids reach or exceed 100/plant by the time sorghum reaches the boot stage.

Regression analyses (Table 4) indicated that peak coccinellid abundance may be predicted by greenbug abundance or a combination of greenbug and corn leaf abundance, looking back to the aphid abundance two weeks prior to the coccinellid peak. When all fields were considered, ignoring whether they were irrigated or rainfed, the regressions indicated that when one greenbug is 

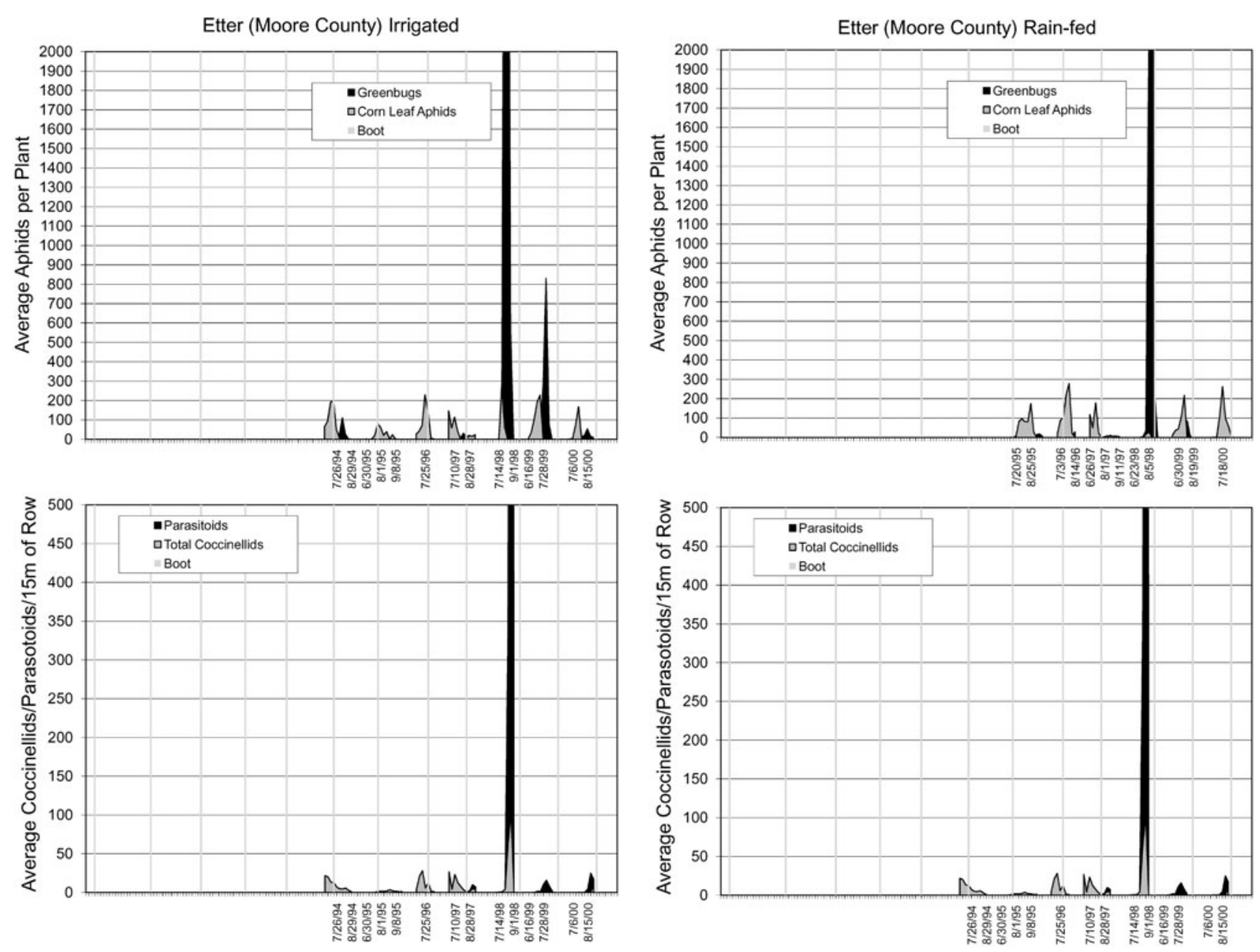

Fig. 3. Greenbug, corn leaf aphid, predacious coccinellid and parasitoid abundance in irrigated grain sorghum fields, Etter, TX, 1995-2000. Sorghum boot stage represented by vertical lines.

added to the system at time $t$, the coccinellid peak abundance increases by 0.033 at time $t+2$. If corn leaf aphids and greenbugs were combined as a single number, included in the equation as separate parameters, or if an indicator variable (I) was added to different fields where corn leaf aphids averaged 100/plant by boot stage ( $I=1$ for corn leaf aphids averaging 100/plant or more by boot stage, 0 if not), the results were similar; the increase in peak coccinellid abundance ranging from 0.034 to 0.037 . A more practical way of looking at these results would be to express the increase in peak coccinellid abundance in terms of an increase of 1000 aphids; e. g. for Equation 1 in Table 4, an addition of 1000 greenbugs at time $t$ increases the peak coccinellid abundance by approximately 35 at $t+2$. Although these regressions were significant, with $p$ ranging from 0.009 to 0.035 , the coefficient of determination $\left(R^{2}\right)$ was very low in all cases, ranging from 0.19 to 0.21 .

Better results were found when the analyses were run with pairs of irrigated and rain-fed fields from the same location. Therefore, instead of lumping 33 "field-years" of information together, we examined 10 pairs of fields where irrigated and rain-fed fields were sampled side-by-

Fig. 4. Greenbug, corn leaf aphid, predacious coccinellid and parasitoid abundance in rain-fed grain sorghum fields, Etter, TX, 1995-2000. Sorghum boot stage represented by vertical lines.

side at the same location. In this analysis, if greenbugs alone were used as the independent variable, one additional greenbug at time $t$ increased peak coccinellid abundance per $15 \mathrm{~m}$ of row at time $t+2$ by $0.024\left(R^{2}=0.77, p\right.$ $=0.024)$. If aphid species are combined, then coccinellid peak abundance per $15 \mathrm{~m}$ of row increased 0.025 at $t+2$ for each aphid added a $t\left(R^{2}=0.77, p=0.025\right)$. If an indicator variable (I) was added as a parameter to the previous equation to distinguish irrigated from rain-fed fields ( $\mathrm{I}=1$ for irrigated fields and 0 for rain-fed fields), the same result is found with a slightly higher $R^{2}$ but a much lower $p$ ( 0.78 and 0.000 , respectively).

Looking at a graph of the regression analyses (Fig. 7) in rain-fed fields vs. irrigated fields, a smaller complement of initial coccinellids was indicated in rain-fed fields. This is plausible and could be due to slower plant development and corn leaf aphid colonization in rain-fed fields, resulting in lower coccinellid oviposition. Although precipitation varies on a yearly basis, irrigated fields invariably receive more moisture than rain-fed fields in the semi-arid environment of the Southern Great Plains.

A graph of the regressions for greenbugs alone vs. a combination of both aphid species indicated that if corn 

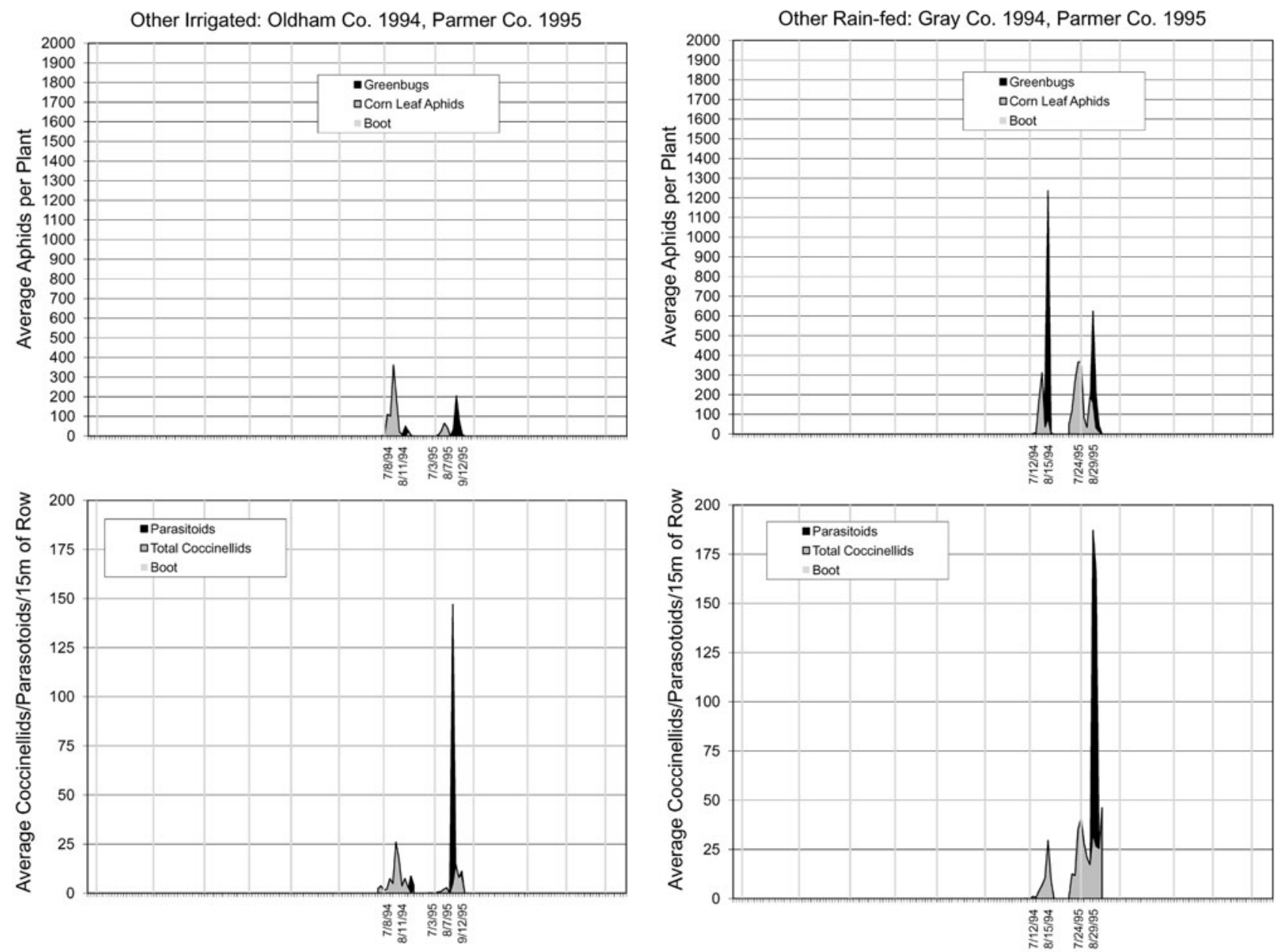

Fig. 5. Greenbug, corn leaf aphid, predacious coccinellid and parasitoid in irrigated grain sorghum fields, Gray, Oldham, and Parmer, Co's, TX, 1994, 1995. Sorghum boot stage represented by vertical lines.

leaf aphids and greenbugs were considered together as a common food source, a better indication of the initial coccinellid complement (y-intercept) was achieved than when greenbugs were considered alone. The greenbugonly regression inferred a higher coccinellid abundance being present when the greenbugs first entered the field, which could be due to the presence of corn leaf aphids that are unaccounted for in this equation (Fig. 8).

The combination of the correlation and regression analyses support the concept that corn leaf aphids are indeed instrumental to greenbug biological control in grain sorghum. Although the correlation analyses give stronger support that the simple regression analyses, the regressions indirectly support the concept. The y-intercepts illustrated in Fig. 8 clearly indicate that if corn leaf aphids are not accounted for, coccinellid abundance in the field is higher when greenbugs first enter the field. Looking at Table 2 and Figs $1-6$, it is obvious that in most years corn leaf aphids are present in the field earlier than greenbugs, or if corn leaf aphids and greenbugs are initially found at the same time, corn leaf aphid abundance is higher than greenbug.

Fig. 6. Greenbug, corn leaf aphid, predacious coccinellid and parasitoid in rain-fed grain sorghum fields, Gray, Oldham, and Parmer, Co's, TX, 1994, 1995. Sorghum boot stage represented by vertical lines.

The results of both the correlation and regression analyses indicate that it is probably better for research projects to experimentally pair irrigated and rain-fed fields in the same location within the same year. Irrigation is a significant factor in the number of aphids observed in a field (compare Figs 1 to 2, 3 to 4 and 5 to 6 ), and the

TABLE 3. Pearson correlation analyses for the relationship between the appearance of the first coccinellid eggs and coccinellid peak abundance to peak corn leaf aphid and greenbug abundance and corn leaf aphids averaging 100/plant in irrigated and rain-fed grain sorghum fields, Texas High Plains, 1998-2000.

\begin{tabular}{lccccc}
\hline & \multicolumn{2}{c}{ Irrigated } & & \multicolumn{2}{c}{ Rain-fed } \\
\cline { 2 - 3 } \cline { 5 - 6 } & First Egg & Pred Peak & & First Egg & Pred Peak \\
\hline R. maidis peak & $\mathbf{0 . 7 0 5}$ & $\mathbf{0 . 6 6 3}$ & & $\mathbf{0 . 6 7 7}$ & $\mathbf{0 . 6 9 3}$ \\
Prob. & $\mathbf{0 . 0 0 7}$ & $\mathbf{0 . 0 0 5}$ & & $\mathbf{0 . 0 1 0}$ & $\mathbf{0 . 0 0 8}$ \\
R. maidis $=100$ & $\mathbf{0 . 7 0 5}$ & $\mathbf{0 . 6 7 7}$ & & $\mathbf{0 . 9 0 9}$ & $\mathbf{0 . 8 6 5}$ \\
Prob. & $\mathbf{0 . 0 0 7}$ & $\mathbf{0 . 0 0 4}$ & & $\mathbf{0 . 0 0 5}$ & $\mathbf{0 . 0 1 2}$ \\
S. graminum peak & 0.316 & $\mathbf{0 . 6 3 8}$ & & 0.167 & 0.470 \\
Prob. & 0.293 & $\mathbf{0 . 0 0 8}$ & & 0.721 & 0.287 \\
\hline
\end{tabular}




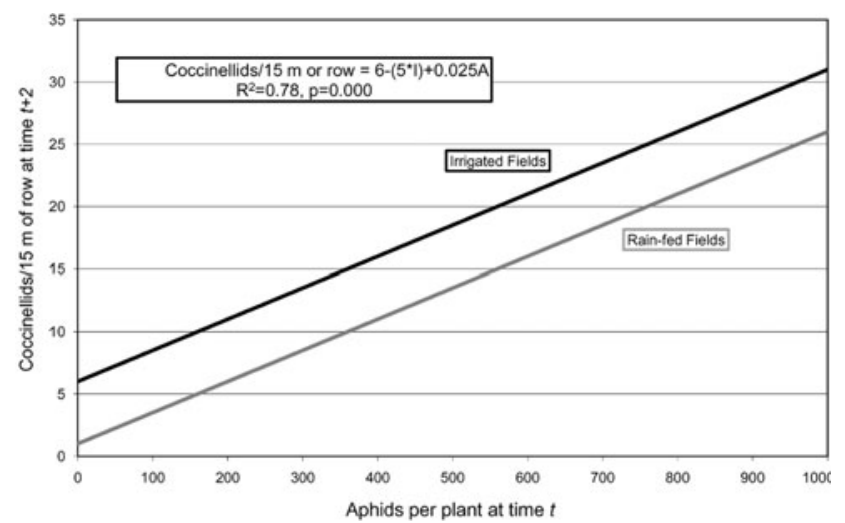

Fig. 7. Comparison of linear regression analyses for predicting coccinellid abundance per $15 \mathrm{~m}$ of row for irrigated and rain-fed grain sorghum fields at time $t+2$ using aphids/plant at $t$ as the independent variable. For irrigated fields $\mathrm{I}=0$, for rain-fed fields $\mathrm{I}=1$.

number of coccinellids that can be expected to be present (Fig. 7).

The results we observed in this research extend the results reported by Kring \& Gilstrap (1986) who found that corn leaf aphids maintained $H$. convergens in sorghum fields. Rice \& Wilde (1988) had similar findings in regard to predators in sorghum. Even with 33 "field years" of data, and 10 years of side-by side comparisons of irrigated and rain-fed grain sorghum fields, there are still questions that need to be answered. We are comfortable concluding that the general "rule of thumb" mentioned above (that greenbug biological control by coccinellids is successful and outbreaks do not occur when corn leaf aphids reach or exceed 100/plant by the time sorghum reaches the boot stage), and believe it can be used with confidence as a management tool. However, the results additionally point to a need to thoroughly assess climatic conditions, and perhaps look at the role non-coccinellid predators might play in the system. Although we did not add such predators as lacewings and syrphid fly larvae to our analyses, there is a chance that these minor predators play a role in specific years.

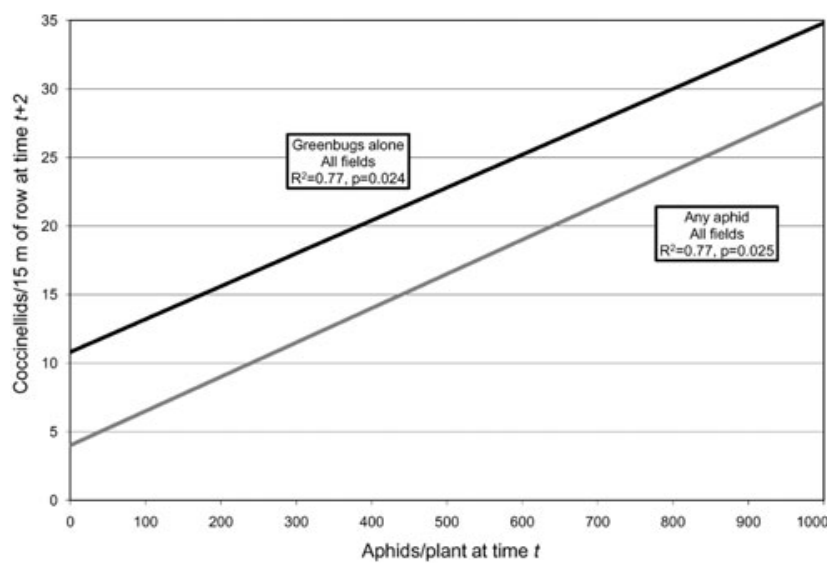

Fig. 8. Comparison of linear regression analyses for predicting coccinellids per $15 \mathrm{~m}$ of row in grain sorghum fields at time $t+2$ using greenbugs alone/plant or any aphid species/plant at $t$ as the independent variable.

ACKNOWLEDGMENTS. In a study encompassing thirteen years of field data collecting, a great number of people are involved. The many summer spent by field crews with the Texas Agricultural Experiment Station Entomology Program at Bushland, TX are truly appreciated. We are indebted to R.W. Behle, R.L. Renn, and D.A. Owings who as Research Associates supervised the many field crews from 1988-1990, 1991-1994, and 1995-2000, respectively. We also acknowledge J.B. Bible, Research Assistant, who participated in each summer's field sampling from 1988-2000. Finally, we thank F.E. Gilstrap and T.J. Kring who provided insightful comments on the research throughout its run.

\section{REFERENCES}

Cate J.H. JR., Bottrell D.G. \& Teetes G.L. 1973: Management of the greenbug on grain sorghum. 1. Testing foliar treatments of insecticides against greenbugs and corn leaf aphids. $J$. Econ. Entomol. 66: 945-951.

Cronholm G., Knutson A., Parker R., Teetes G. \& Pendleton B. 1998: Managing insect and mite pests of Texas sorghum. Tex. Agric. Exp. Stat. Bull. B-1220. 26 pp.

Buschman L.L. \& DePew L.J. 1990: Outbreaks of Banks grass mite (Acari: Tetranychidae) in grain sorghum following insecticide applications. J. Econ. Entomol. 83: 1570-1574.

TABLE 4. Linear regressions of aphid variables on coccinellid peak abundance.

\begin{tabular}{|c|c|c|c|}
\hline Equation $^{1}$ & $R^{2}$ & $p$ & Result of adding one indicated aphid(s) at time $t$ on C at time $t+2$ \\
\hline \multicolumn{4}{|c|}{ All fields considered, irrigation ignored. } \\
\hline 1. $\mathrm{C}=29.5+0.033 \mathrm{SG}$ & 0.19 & 0.010 & $\mathrm{C}$ increases by 0.033 \\
\hline 2. $\mathrm{C}=20.1+0.034 \mathrm{~A}$ & 0.20 & 0.009 & $\mathrm{C}$ increases by 0.034 \\
\hline 3. $\mathrm{C}=20.4+0.034 \mathrm{SG}+0.037 \mathrm{RM}$ & 0.20 & 0.035 & C increases by 0.034 or 0.037 , for SG or RM, respectively \\
\hline 4. $\mathrm{C}=11.3+24 \mathrm{I}+0.037 \mathrm{~A}$ & 0.21 & 0.027 & $\mathrm{C}$ increases by 0.037 RM $>100$ /plant by boot stage increases $\mathrm{C}$ by 24 \\
\hline \multicolumn{4}{|c|}{ Paired field analyses ( 1 irrigated, 1 rain-fed field), 10 comparisons, 20 fields. } \\
\hline 5. $\mathrm{C}=10.8+0.024 \mathrm{SG}$ & 0.77 & 0.024 & $\mathrm{C}$ increases by 0.024 \\
\hline 6. $\mathrm{C}=4+0.025 \mathrm{~A}$ & 0.77 & 0.025 & $\mathrm{C}$ increases by 0.025 , irrigation ignored \\
\hline 7. $\mathrm{C}=6-(5 * \mathrm{I})+0.025 \mathrm{~A}$ & 0.78 & 0.000 & $\mathrm{C}$ increases by 0.025 , irrigation considered. Irrigation increases $\mathrm{C}$ by 5 \\
\hline
\end{tabular}

${ }^{1} \mathrm{~A}=$ any aphid species, $\mathrm{C}=$ coccinellid peak abundance, $\mathrm{RM}=R$. maidis (corn leaf aphid), $\mathrm{SG}=S$. graminum (greenbug).

For Eq. 4, if $\mathrm{RM}>100$ by boot stage $\mathrm{I}=1$ otherwise $\mathrm{I}=0$. For Eq. 7 , if irrigated $\mathrm{I}=1$ otherwise $\mathrm{I}=0$. 
Kring T.J. \& Gilstrap F.E. 1986: Beneficial role of corn leaf aphid, Rhopalosiphum maidis (Fitch) (Homoptera: Aphididae) in maintaining Hippodamia spp. (Coleoptera: Coccinellidae) in grain sorghum. Crop Prot. 5: 125-128.

Kring T.J., Gilstrap F.E. \& Michels G.J. JR. 1985: Role of indigenous coccinellids in regulating greenbugs (Homoptera: Aphididae) on Texas grain sorghum. J. Econ. Entomol. 78: 269-273.
Rice M.E. \& WiLde G.E. 1988: Experimental evaluation of predators and parasitoids in suppressing greenbugs (Homoptera: Aphididae) in sorghum and wheat. Environ. Entomol. 17: 836-841.

SAS. 1999: Cary, NC. Version 8.0.

SPSS. 2007: Chicago, IL. Version 13.0.

WILDE G. \& OHAIGU C. 1976: Relation of corn leaf aphid to sorghum yields. J. Econ. Entomol. 69: 195-197.

Received October 16, 2007; revised and accepted May 6, 2008 